\title{
Synthesis of electrophoretic poly(ester-sulfone) gel via thiol-yne click gelation
}

\author{
Yosuke Mano, Yu Nagao and Akinori Takasu
}

The thiol-ene 'click' reaction is well known as an efficient method for synthesizing certain functional polymers. In this study, we performed the ternary 'click' copolymerization (gelation) of bis(butynyl) methylsuccinate (BYM), bis(butenyl) methylsuccinate and 3,6-dioxa-1,8-octanedithiol (TEGDT) to synthesize a poly(ester-sulfide) gel. In this process, an alkenyl sulfide was initially formed before undergoing a second thiol addition to afford a poly(ester-sulfide) gel, which finally afforded the poly(ester-sulfone) gel after oxidation using Oxone. The gelation process was characterized via a model reaction using 1-octyne, 1-octene and TEGDT. The results clearly indicate that a thiol first added to the BYM unit during the click gelation and that the addition of the second thiol to the subsequent alkenyl sulfide was faster than the addition to the alkene. The synthesized poly(ester-sulfone) gel was anode-selectively deposited onto a stainless-steel electrode by electrophoretic deposition, although the parent poly(ester-sulfide) gel was not.

Polymer Journal (2014) 46, 682-687; doi:10.1038/pj.2014.54; published online 16 July 2014

\section{INTRODUCTION}

Current portable electronic devices, such as cellular phones and laptop computers, rely on batteries. Although rechargeable battery technology has experienced significant advances from nickel cadmium to today's lithium polyelectrolyte, rechargeable batteries still face serious drawbacks that must be overcome, ${ }^{1,2}$ of which limited battery capacity is one of the most pressing. ${ }^{3}$ Because liquid electrolytes are used in most battery cells, developing a solid battery container that is capable of preventing leakage and degradation of the electrolytes while simultaneously offering reduced battery weight is also a challenge. ${ }^{4}$ Moreover, organic liquid electrolytes are hazardous because of their risk of ignition when heated, which is a serious problem for large-scale battery banks, such as those employed for power production from wind or solar energy. 5,6 Thus the development of a novel solid-state electrolyte could lead to a battery with high ionic conductivity, thermal stability, nonflammability, safety and durability. We focused on sulfone-based solid electrolytes, because tetramethylene sulfone and ethylmethyl sulfone exhibit high ionic conductivity and excellent oxidation potentials. $^{7-9}$ Some organic sulfones have been investigated for high-voltage cells owing to their low volatility and high resistance to electrochemical oxidation. ${ }^{10,11}$ Notably, organic sulfones with different length oligo(ethylene glycol) segments have been synthesized and tested for use in rechargeable lithium batteries. ${ }^{12}$

We have previously developed methods for the direct polycondensation of dicarboxylic acids with diols at moderate temperatures and catalyzed by rare-earth metals with electron-withdrawing ligands to afford specific aliphatic polyesters with number-average molecular weights $\left(M_{\mathrm{n}}\right)$ of $>2.0 \times 10^{4} \cdot{ }^{13-18}$ We have also reported on the kinetically controlled chemoselective polycondensation of monomers with carbon-carbon double bonds, ${ }^{19}$ pendant bromo $^{19}$ or hydroxy ${ }^{20,21}$ groups and on the facile one-step chemoselective polycondensation of diols and the dicarboxylic acid thiomalic acid under mild conditions catalyzed by scandium trifluoromethanesulfonate $\left(\mathrm{Sc}(\mathrm{OTf})_{3}\right)$ to yield polyesters bearing pendant mercapto groups $\left(M_{\mathrm{n}}=1.4 \times 10^{4}, M_{\mathrm{w}} / M_{\mathrm{n}}=1.5\right),{ }^{22}$ which, by subsequent crosslinking of the mercapto groups using thiocarbonyldiimidazole, produces a 'Reversible Addition Fragmentation chain-Transfer (RAFT) gel' with trithiocarbonate crosslinks. ${ }^{22}$ Due to the tendency of sulfone or sulfide units to coordinate to Lewis acids, their introduction into aliphatic polyesters via dehydration polycondensation was difficult. Thus we have recently reported the facile synthesis of poly(ester-sulfones) via the thiol-ene click polymerization of bis(butenyl) methylsuccinate (BEM) with several dithiols and subsequent Oxone oxidation (Figure 1). ${ }^{23}$ Additionally, we found that the poly(ester-sulfone) was stable in an electrical field and exhibited unique anode-selective electrophoretic behavior in the first report addressing a nonionic electrophoretic polymer (Figure 1). ${ }^{23}$ This research background motivated us to explore electric field-sensitive poly(ester-sulfone) gels. In this article, we report on the preparation of a poly(ester-sulfide) gel via thiol-yne/ ene click polymerization (gelation), in which the alkyne units are transformed into alkane units via alkenyl sulfide through successive thiol-yne and thiol-ene click reactions in the poly(ester-sulfide) 


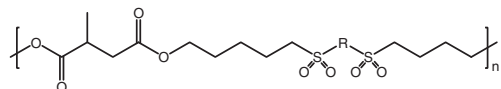

Methylsuccinic acid (MSA)-based (BEM-containing) aliphatic poly(ester-sulfone)s (1-4) 1: $\mathrm{R}=\left(\mathrm{CH}_{2}\right)_{2}, 2: \mathrm{R}=\left(\mathrm{CH}_{2}\right)_{3}, 3: \mathrm{R}=\left(\mathrm{CH}_{2}\right)_{4}, 4: \mathrm{R}=\left(\mathrm{CH}_{2}\right)_{5}$

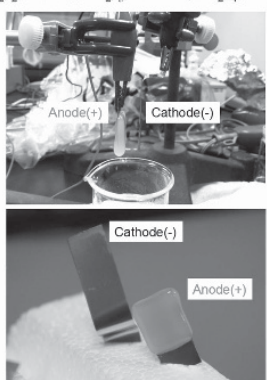

Figure 1 Anode-selective electrophoretic deposition of poly(ester-sulfone) from the suspension. ${ }^{23} \mathrm{~A}$ full color version of this figure is available at the Polymer Journal journal online.

segments. This transformation was followed by oxidation of the resulting poly(ester-sulfide) to prepare the expected poly(ester-sulfone) gel (Figure 2). ${ }^{23}$ The main chain of this gel consisted of sulfone, ethylene glycol and ester functions, which is a similar composition to previously reported organic sulfones with various length oligo(ethylene glycol) segments for use in rechargeable lithium batteries. ${ }^{12}$ In this article, we particularly focused on investigating the Oxone oxidation to prepare the poly(ester-sulfone) gel, even in the heterogeneous state, and on the electrophoretic behavior of the poly(ester-sulfone) gel using the electrophoretic deposition (EPD) technique.

\section{EXPERIMENTAL PROCEDURE}

\section{Materials and methods}

Chloroform, Oxone, 1-butanol, dry N,N-dimethylformamide (DMF) and $\mathrm{Sc}(\mathrm{OTf})_{3}$ were purchased from Wako Pure Chemical Industries, Ltd (Osaka, Japan). Methylsuccinic acid, 3-buten-1-ol, 3-butyn-1-ol and 3,6-dioxa-1,8octanedithiol (TEGDT) were purchased from the Tokyo Chemical Industry Co., Ltd (Tokyo, Japan). 2,2'-Azobisisobutyronitrile (AIBN), toluene and hexane were purchased from Nacalai Tesque Inc. (Kyoto, Japan). Toluene was distilled before use. AIBN was purified by recrystallization from methanol. ${ }^{1} \mathrm{H}$ nuclear magnetic resonance (NMR) spectra were acquired at $27^{\circ} \mathrm{C}$ using a Bruker Avance DPX200 spectrometer (Bruker, Billerica, MA, USA) (200 MHz). Tetramethylsilane was used as the internal standard (0 p.p.m.). Fourier transformation infrared (FT-IR) spectra of the polyesters in $\mathrm{KBr}$ pellets were obtained using a JASCO/IR-430 spectrometer (JASCO, Tokyo, Japan). Attenuated total reflectance (ATR) spectra of the poly(ester-sulfone) gel were obtained using a JASCO/ATR-300/H spectrometer equipped with the JASCO/ IR-430 spectrometer. The $M_{\mathrm{n}}$ and the polydispersity index $\left(M_{\mathrm{w}} / M_{\mathrm{n}}\right)$ of each polymer were determined by size-exclusion chromatography using a Tosoh DP8020 pump system, an RI (Tosoh RI-8020) detector, a TSK-GEL SUPERMULTIPOREHZ-M column (Tosoh Corp., Tokyo, Japan) (eluent, chloroform; flow rate, $0.35 \mathrm{ml} \mathrm{min}^{-1}$; temperature, $40^{\circ} \mathrm{C}$ ) or a TSK-GEL $\alpha-3000$ column (eluent, $0.05 \%$ (w/v) LiBr/DMF; flow rate, $0.5 \mathrm{ml} \mathrm{min}^{-1}$; temperature, $40{ }^{\circ} \mathrm{C}$ ). The columns were calibrated using polystyrene standards. Differential scanning calorimetry (DSC) was performed from $-90^{\circ}$ to $180^{\circ} \mathrm{C}$ to $-90^{\circ} \mathrm{C}$ at $10^{\circ} \mathrm{C} \mathrm{min}^{-1}$ using a DSC6220S calorimeter (Seiko Instruments Inc., Chiba, Japan). The instrument was calibrated with indium and tin. Each sample weighed between 7 and $9 \mathrm{mg}$ and was contained in an aluminum pan covered with a lid within the calorimeter. The glass-transition temperature $\left(T_{\mathrm{g}}\right)$ was taken as the inflection point of the DSC heat-capacity jump. The melting temperature $\left(T_{\mathrm{m}}\right)$ was defined as the minimum point in the endothermic trough. Thermogravimetric analyses (TGA) were performed under nitrogen at $10{ }^{\circ} \mathrm{C} \mathrm{min}^{-1}$ between 20 and $600^{\circ} \mathrm{C}$ (TG/DTA 220U; Seiko Instruments Inc.).

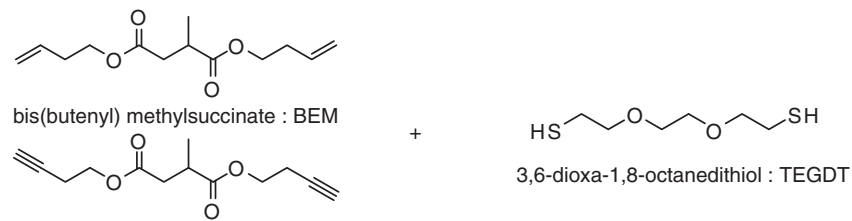

bis(butynyl) methylsuccinate : BYM

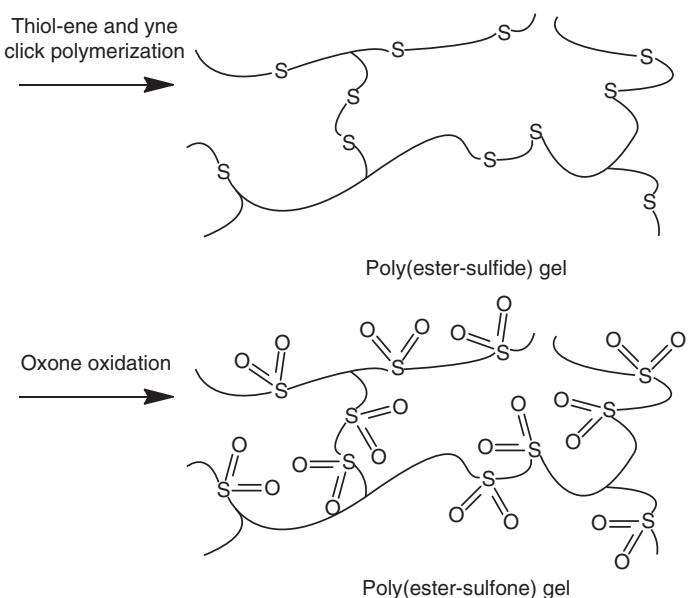

Figure 2 Thiol-yne/ene click polymerization (gelation) and subsequent oxidation to poly(ester-sulfone) gel.

Table 1 Preparation of poly(ester-sulfide) gel via thiol-yne click gelation $^{\mathrm{a}}$

\begin{tabular}{lccc}
\hline Run & $\begin{array}{c}{[B E]_{O}:[B Y M]_{0}:[T E G D T]_{O}} \\
\text { (molar ratio) }\end{array}$ & $\begin{array}{c}\text { Remaining double bond } \\
\text { (vinyl sulfide) }^{\mathrm{b}}(\%)\end{array}$ & Gelation \\
\hline 1 & $1: 1: 2$ & 20 & - \\
2 & $1: 1: 3$ & $\mathrm{NA}^{\mathrm{c}}$ & + \\
3 & $1: 1: 4$ & $\mathrm{NA}^{\mathrm{c}}$ & + \\
4 & $1: 1: 5$ & 0 & - \\
5 & $3: 2: 10$ & 0 & - \\
6 & $4: 1: 10$ & 0 & - \\
\hline
\end{tabular}

Abbreviations: BEM, bis(butenyl) methylsuccinate; BYM, bis(butynyl) methylsuccinate; NA, not available; TEGDT, 3,6-dioxa-1,8-octanedithiol.

aln toluene, at $70^{\circ} \mathrm{C}$ for $40 \mathrm{~min}$

betermined by ${ }^{1} \mathrm{H}$ nuclear magnetic resonance spectroscopy.

cThe percentage of remaining double bond could not be determined for runs 2 and 3 owing to gelation.

\section{Preparation of BEM}

Methylsuccinic acid $(2.0 \mathrm{~g}, 15 \mathrm{mmol}), \mathrm{Sc}(\mathrm{OTf})_{3}(74 \mathrm{mg}, 0.15 \mathrm{mmol})$ and 3-buten-1-ol $(4.3 \mathrm{~g}, 60 \mathrm{mmol})$ were added to a 50 -ml round-bottom flask. The mixture was stirred at $60^{\circ} \mathrm{C}$ for $12 \mathrm{~h}$ under reduced pressure $(90 \mathrm{~mm} \mathrm{Hg})$ and then diluted with $30 \mathrm{ml}$ of chloroform, washed with $10 \mathrm{ml}$ of saturated $\mathrm{NaHCO}_{3(\mathrm{aq})}$ and dried over $\mathrm{MgSO}_{4}$. After filtration and solvent evaporation, BEM was obtained as a colorless syrup with a $91 \%$ yield $(3.3 \mathrm{~g}) .{ }^{1} \mathrm{H}$ NMR $\left(200 \mathrm{MHz}\right.$ in $\left.\mathrm{CDCl}_{3}\right) \delta_{\mathrm{H}}$ (p.p.m.): 5.89-5.68 (m, C $\left.=\mathrm{CHCH}_{2}, 2 \mathrm{H}\right), 5.16-5.05$ $\left(\mathrm{m}, \quad \mathrm{CH}_{2}=\mathrm{C}, 4 \mathrm{H}\right), \quad 4.19-4.10 \quad\left(\mathrm{~m}, \quad \mathrm{CH}_{2} \mathrm{CH}_{2} \mathrm{OC}=\mathrm{O}, 4 \mathrm{H}\right), 2.89 \quad(\mathrm{~m}$, $\left.\mathrm{O}=\mathrm{CCH}\left(\mathrm{CH}_{3}\right) \mathrm{CH}_{2}, \quad 1 \mathrm{H}\right), 2.73\left(\mathrm{dd}, \mathrm{O}=\mathrm{CCH}_{2} \mathrm{CH}\left(\mathrm{CH}_{3}\right), \quad 1 \mathrm{H}, \quad 8.0\right.$ and $16 \mathrm{~Hz}), 2.45-2.34\left(\mathrm{~m}, \mathrm{O}=\mathrm{CCH}_{2} \mathrm{CH}\left(\mathrm{CH}_{3}\right)\right.$ and $\left.\mathrm{C}=\mathrm{CHCH}_{2} \mathrm{CH}_{2}, 5 \mathrm{H}\right], 1.21$ (d, $\left.3 \mathrm{H}, \mathrm{C}\left(\mathrm{CH}_{3}\right), 7.1 \mathrm{~Hz}\right)$.

Preparation of bis(butynyl) methylsuccinate (BYM)

To a $50 \mathrm{ml}$ round-bottom flask were added methylsuccinic acid $(2.5 \mathrm{~g}$, $19 \mathrm{mmol}), \mathrm{Sc}(\mathrm{OTf})_{3}(93 \mathrm{mg}, 0.19 \mathrm{mmol})$ and 3-butyn-1-ol $(5.4 \mathrm{~g}, 77 \mathrm{mmol})$. 
The reaction mixture was stirred at $60^{\circ} \mathrm{C}$ for $12 \mathrm{~h}$ under reduced pressure $(25 \mathrm{mmHg})$. After the reaction mixture was diluted with $30 \mathrm{ml}$ of chloroform, the solution was washed with $10 \mathrm{ml}$ of water saturated with $\mathrm{NaHCO}_{3}$ and then dried over $\mathrm{MgSO}_{4}$. After filtration and solvent evaporation, BYM was obtained as an auburn liquid with an $84 \%$ yield $(3.76 \mathrm{~g}) .{ }^{1} \mathrm{H}$ NMR $\left(200 \mathrm{MHz}\right.$ in $\left.\mathrm{CDCl}_{3}\right) \delta_{\mathrm{H}}$ (p.p.m.): 4.19 (t, $\left.\mathrm{CH}_{2} \mathrm{CH}_{2} \mathrm{OC}=\mathrm{O}, 4 \mathrm{H}, 6.7 \mathrm{~Hz}\right), 2.93$ $\left(\mathrm{m}, \mathrm{O}=\mathrm{CCH}\left(\mathrm{CH}_{3}\right) \mathrm{CH}_{2}, \quad 1 \mathrm{H}\right), \quad 2.78 \quad\left(\mathrm{dd}, \mathrm{O}=\mathrm{CCH}_{2} \mathrm{CH}\left(\mathrm{CH}_{3}\right), \quad 1 \mathrm{H}, \quad 8.1\right.$ and $16 \mathrm{~Hz}), 2.57-2.50\left(\mathrm{~m}, \mathrm{CH}_{2} \mathrm{C} \equiv \mathrm{C}, 4 \mathrm{H}\right), 2.45\left(\mathrm{dd}, \mathrm{O}=\mathrm{CCH}_{2} \mathrm{CH}\left(\mathrm{CH}_{3}\right)\right.$, $1 \mathrm{H}, 6.0$ and $16 \mathrm{~Hz}), 2.00(\mathrm{t}, \mathrm{C} \equiv \mathrm{CH}, 2 \mathrm{H}, 2.5 \mathrm{~Hz}), 1.24\left(\mathrm{~d}, \mathrm{C}\left(\mathrm{CH}_{3}\right), 3 \mathrm{H}, 7.1 \mathrm{~Hz}\right)$.

Synthesis of the poly(ester-sulfide) gel

The gelation was performed using various initial molar ratios; an example (Table 1, run 2) follows. BEM ( $0.50 \mathrm{mmol})$, BYM ( $0.50 \mathrm{mmol})$, TEGDT $(1.5 \mathrm{mmol})$ and AIBN $(0.030 \mathrm{mmol})$ were mixed together in $1 \mathrm{ml}$ of distilled toluene, and the mixture was charged to a $10-\mathrm{ml}$ round-bottom flask. After stirring the mixture at $70{ }^{\circ} \mathrm{C}$ for $40 \mathrm{~min}$ under a nitrogen atmosphere, a transparent organogel was obtained. The gel preparations were dried under vacuum. The product was characterized by FT-IR spectroscopy, and its thermal properties were determined using DSC and TGA measurements (Supplementary Figures S1 and S2).

\section{Oxone oxidation of the poly(ester-sulfide) gel to the} poly(ester-sulfone) gel

The mechanically milled (powder size $<1 \mathrm{~mm}$ ) poly(ester-sulfide) gel $\left(9.3 \times 10^{2} \mathrm{mg}\right.$, sulfide $\left.2.2 \mathrm{~mol}\right)$, which was prepared from run 2 in Table 1 , and Oxone $(2.7 \mathrm{~g}, 4.4 \mathrm{mmol})$ in DMF $(18 \mathrm{ml})$ were added to a $30-\mathrm{ml}$ roundbottom flask. After stirring at $40^{\circ} \mathrm{C}$ for $12 \mathrm{~h}$, the mixture was washed with distilled water in a Soxhlet apparatus for $24 \mathrm{~h}$. After freeze-drying, the poly(ester-sulfone) gel was obtained as a white solid with a $43 \%$ yield $\left(4.0 \times 10^{2} \mathrm{mg}\right)$. The product was characterized by FT-IR spectroscopy, and its thermal properties were determined using DSC and TGA measurements (Supplementary Figures S1 and S2).
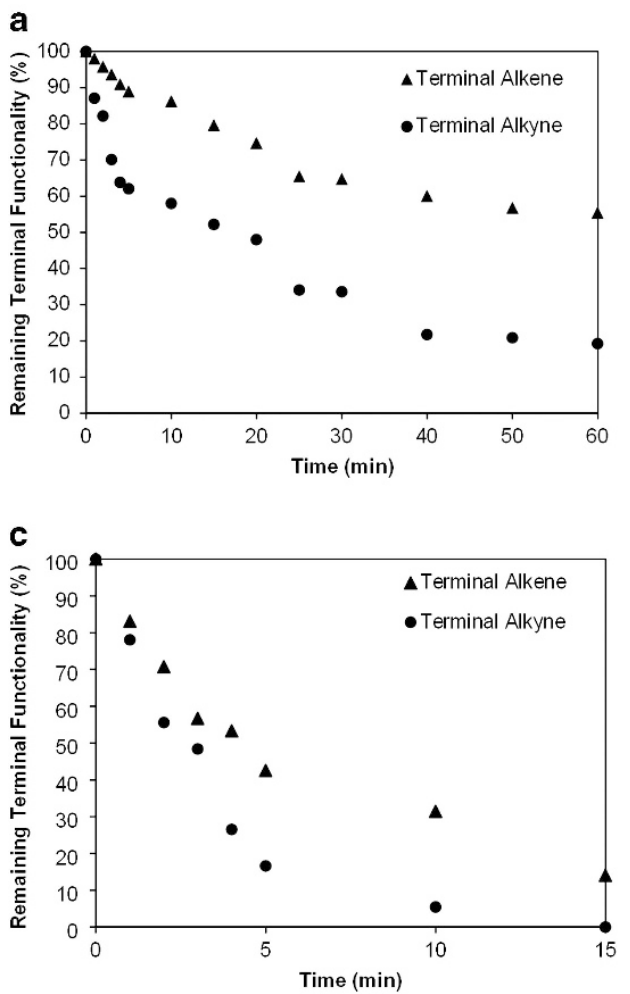

EPD of fractured poly(ester-sulfone) gel on steel electrodes The fabricated and fractured (powder size $<1 \mathrm{~mm}$ ) poly(ester-sulfone) gel (10 mg) was immersed in $4 \mathrm{ml}$ of DMF with stirring for $15 \mathrm{~min}$ at $80^{\circ} \mathrm{C}$ to obtain the dispersed swollen gel. With stirring, the swollen poly(ester-sulfone) gel fractions were deposited onto stainless-steel electrodes by EPD according to our previously reported procedure for poly(ester-sulfone) using a distance between the electrodes of $7.5 \mathrm{~mm}$ and a deposition time of $90 \mathrm{~s}$ at a voltage of $30 \mathrm{~V}^{23}$ The depositions were carried out on $0.2 \times 7.5 \times 15 \mathrm{~mm}^{3}$ stainless-steel SUS 301 electrodes obtained from The Japan Metal Service SA (Saitama, Japan). At least three independent experiments were conducted to determine the reproducibility.

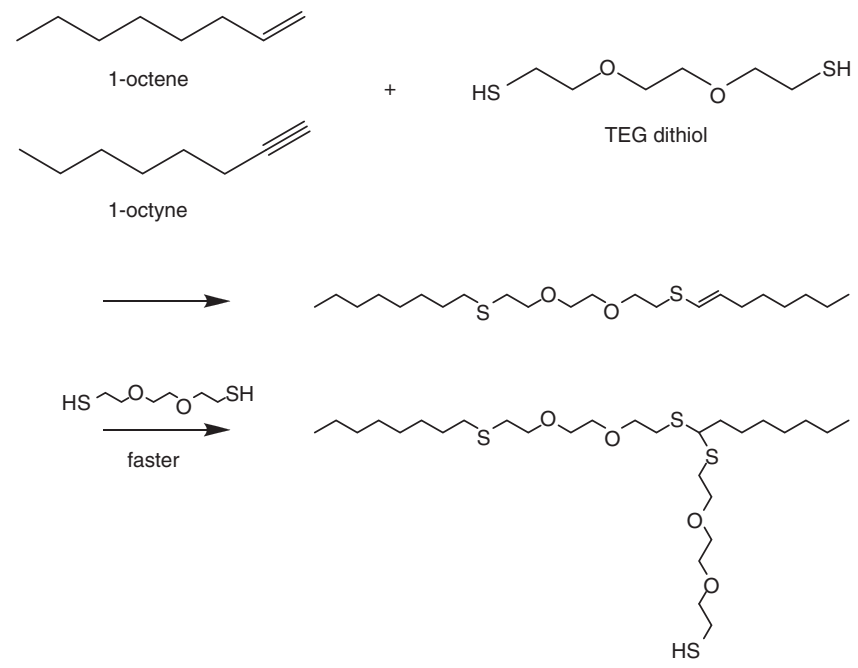

Scheme 1 Model reaction using 1-octen, 1-octyn and TEGDT.
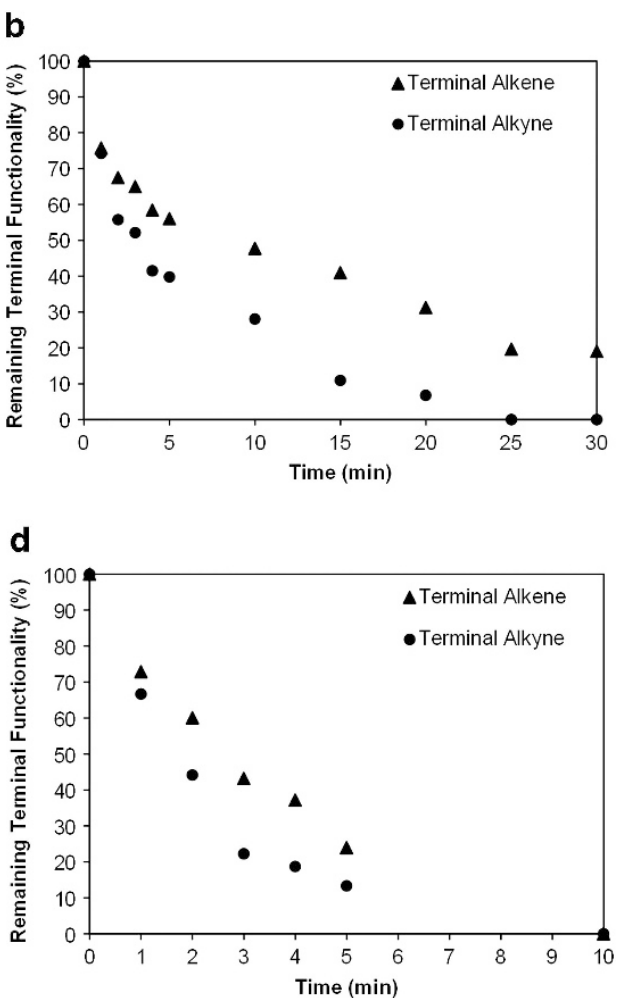

Figure 3 Remaining terminal functionality in the reaction mixture of BEM, BYM, and TEGDT during the curing of various molar ratios of reactive monomer ([BEM] $\left.]_{0}:[B Y M]_{0}:[T E G D T]_{0}\right)$ of (a) $1: 1: 2$, (b) $1: 1: 3$, (c) $1: 1: 4$ and (d) $1: 1: 5$. 
a

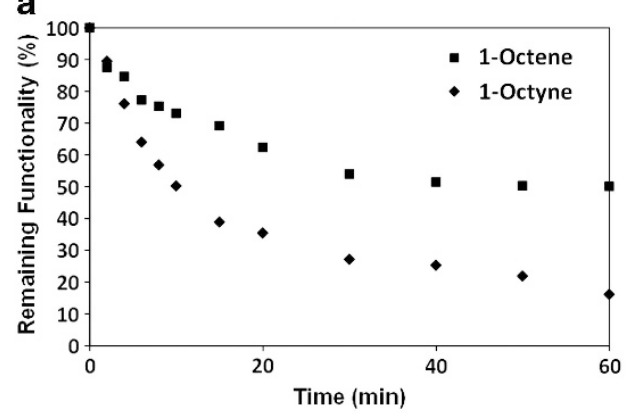

b

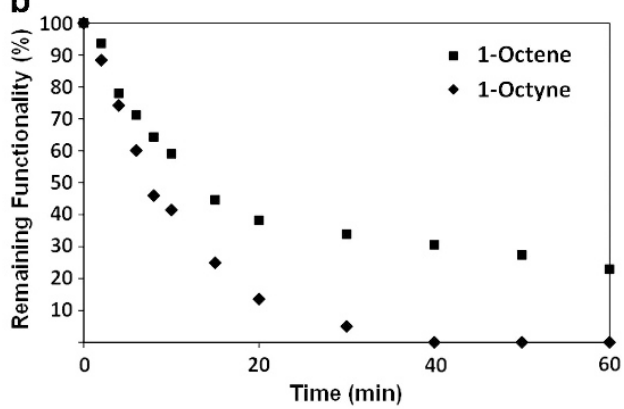

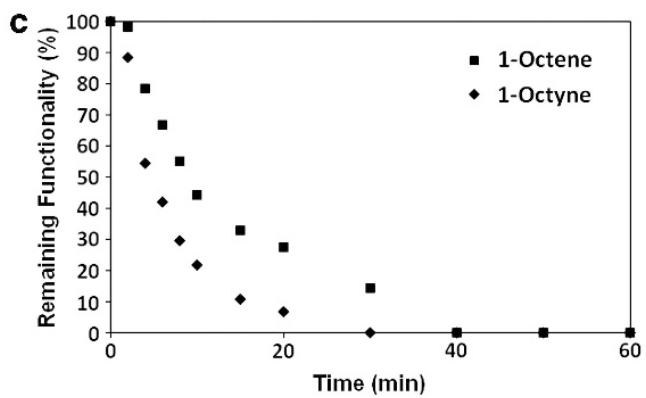

Figure 4 Remaining functionality in the reaction mixture of 1-octyne (a) $1: 1: 1$, (b) $1: 1: 1.5$ and (c) $1: 1: 2$ [1-octene $]_{0}:[1 \text {-octyne }]_{0}:[T E G D T]_{0}$.

\section{RESULTS AND DISCUSSION}

\section{Preparation of poly(ester-sulfone) gel}

The poly(ester-sulfide) gel samples were prepared through the ternary thiol-yne/ene click polymerization (gelation) of BEM, BYM and TEGDT monomer mixtures at $70{ }^{\circ} \mathrm{C}$ for $45 \mathrm{~min}$. BEM, BYM and TEGDT in a molar ratio of 1:1:3 or 1:1:4 were reacted in toluene with AIBN as an initiator at $70^{\circ} \mathrm{C}$ for $45 \mathrm{~min}$ to afford a transparent organogel. However, in the case of other molar ratios, the expected gelation did not occur, even after $2 \mathrm{~h}$ of reaction. These results indicated that gelation can be achieved using a moderate excess of dithiol monomer, TEGDT and equimolar amounts of diene and diyne monomers, BEM and BYM $\left([\mathrm{BEM}]_{0}:[\mathrm{BYM}]_{0}:[\mathrm{TEGDT}]_{0}=1: 1: 3\right.$ or 1:1:4) (runs 2 and 3 in Table 1). Conversely, with the larger excess of TEGDT, we could not obtain a poly(ester-sulfide) gel $\left([\mathrm{BEM}]_{0}:[\mathrm{BYM}]_{0}:[\mathrm{TEGDT}]_{0}=1: 1: 5\right.$, run 4 in Table 1$)$, because the excess TEGDT did not participate as the cross-linker but instead formed branches during the thiol-yne/ene polymerization. This result was strongly supported by the ${ }^{1} \mathrm{H}$ NMR analysis, which indicated the percentage of double bond (internal alkenyl sulfide) units remaining in the main chain (run 4 in Table 1). In the presence of excess TEGDT, most alkenes were consumed by excess thiol to afford branches, and the expected gelation did not occur. Therefore the remaining double bonds were not observed in the ${ }^{1} \mathrm{H}$ NMR spectrum of run 4 . With respect to the content of BYM units in the click polymerization (gelation), when the BYM ratio ([BEM $]_{0}:[\mathrm{BYM}]$ ${ }_{0}:\left[\right.$ TEGDT] ${ }_{0}$ ) was decreased to 3:2:10 (run 5), 4:1:10 (run 6) and 10:1:20 (run 7), gelation was also not observed due to the lower crosslinking density.

To monitor the gelation process, the remaining (unreacted) terminal functionality was followed by ${ }^{1} \mathrm{H}$ NMR spectroscopy during the step-growth (click) polymerization before gelation occurred (Figure 3). This measurement was performed for equimolar mixtures of BYM and BEM with an excess of the dithiol $\left([\mathrm{BYM}]_{0}:[\mathrm{BEM}]_{0}:[\mathrm{TEGDT}]_{0}=1: 1: 2,1: 1: 3,1: 1: 4\right.$ and $1: 1: 5$ in runs $1-4$, respectively, as shown in Figure 3 ) because two equivalents of thiol (two molar equivalents of TEGDT) is consumed by each alkyne (one molar equivalent of BYM) according to the mechanism (Figure 2). The thiol-yne reaction incorporates a thiol-ene addition, but an additional propagation cycle is required. An alkenyl sulfide is formed in the first cycle, which then undergoes a second thiol addition to afford the final product. Kinetic investigation of the ultraviolet-initiated radical addition of thiols to various alkynes revealed that the second addition proceeds approximately three times faster than the first addition. ${ }^{24}$ Rapid consumption of both BYM and BEM is observed within several minutes. As the reaction proceeds, BYM is introduced into the main chain through the addition of a thiyl radical to an alkyne to afford a reactive double bond (alkenyl sulfide unit), thereby leading to gelation via the thiol-ene click reaction. The results are presented in Figure 3, and it appears that the consumption rate of the terminal alkyne was apparently faster than that of the terminal alkene (see also runs $1-4$, Table 1 ). The results support the conclusion that the second addition of thiol proceeds faster than the additions to terminal alkenes in the thiol-yne/ ene click polymerization (gelation), that is, when BYM units are incorporated into the poly(ester-sulfide) backbone, the incorporated vinyl sulfide react faster than the terminal alkenes attributed to BEM units.

\section{Model reactions}

To confirm that alkyne termini are consumed faster than alkene termini, a model reaction was conducted using TEGDT, 1-octene and 1-octyne (Scheme 1 and Figure 4). Similar to that observed during the click polymerization (gelation), it appears that 1-octyne is consumed faster than 1-octene, because the alkenyl sulfide derived from 1-octyne and TEGDT is added by the other thiol faster than 1-octene. For example, when a molar ratio $\left([1 \text {-octene }]_{0}:[1 \text {-octyne }]_{0}:[\text { TEGDT }]_{0}\right)$ of 1:1:1 was reacted, $20 \%$ of the 1 -octyne remained after $60 \mathrm{~min}$, which implies the consumption of $80 \%$ of the TEGDT because two thiol equivalents is consumed by each alkyne. Therefore, from the calculation, a maximum of $40 \%(20 \% \times 2)$ of 1 -octene may have been 


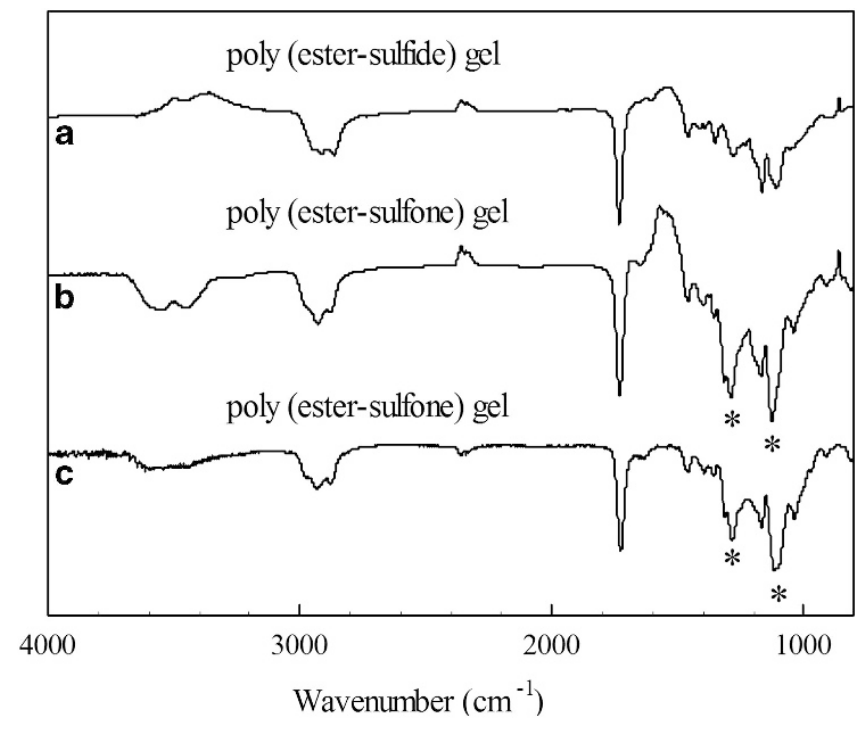

Figure 5 FT-IR spectra of (a) poly(ester-sulfide) gel and (b) poly(estersulfone) gel and ATR spectrum of (c) poly(ester-sulfone) gel (run 2 , Table 1).
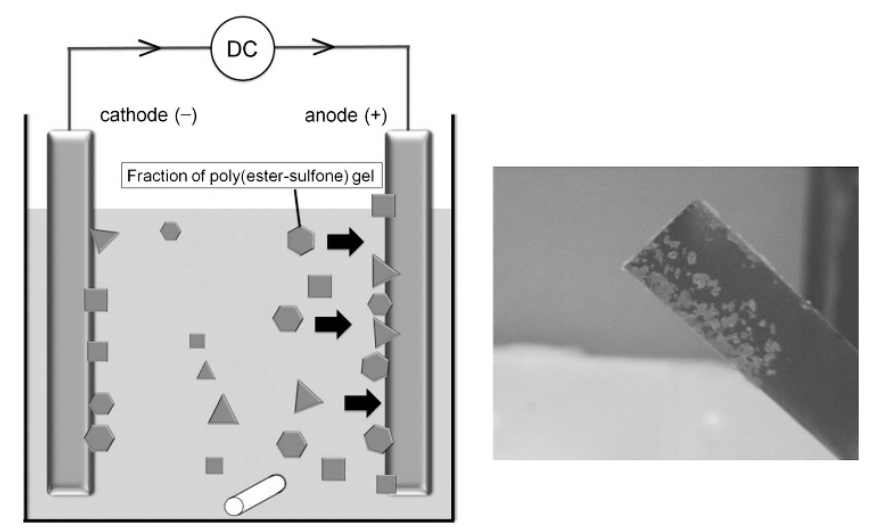

Figure 6 Schematic representation of the electrophoretically controlled deposition of the fractured (powder size $<1 \mathrm{~mm}$ ) poly(ester-sulfone) gel in DMF with stirring and photograph of the anode. A full color version of this figure is available at the Polymer Journal journal online.

consumed, leaving the remaining 1-octene (60\%) unreacted. As shown in Figure $4 \mathrm{a}, 50 \%$ of 1 -octene remained after $60 \mathrm{~min}$, which did not show serious discrepancy with the theoretical calculation. As shown in Figure $4 \mathrm{c}$, when using an excess of TEGDT ([1-octene $]_{0}$ : $\left.[1 \text {-octyne }]_{0}:[\text { TEGDT }]_{0}=1: 1: 2\right)$, 1-octyne was completely consumed after $30 \mathrm{~min}$, and the remaining 1.0 equivalent (to 1-octene) of TEGDT completely consumed 1 -octene after $60 \mathrm{~min}$. Based on the results, we concluded that when the alkyne reacts with the thiol, it does so through the consecutive addition of two equivalents of thiol to an alkyne to afford branches and thus giving rise to gelation. During the model reaction performed under this reaction condition, the vinyl sulfide was not observed in the ${ }^{1} \mathrm{H}$ NMR measurements. We considered that the second addition is much faster than the first addition, because the kinetic investigation of the ultraviolet-initiated radical addition of thiols to various alkynes revealed that the second addition proceeds approximately three times faster than the first addition. $^{24}$
Table 2 Adhesive capacity and selectivity of the poly(ester-sulfone) gel onto electrode by EPD ${ }^{a}$

\begin{tabular}{lcccc}
\hline & & \multicolumn{2}{c}{ EPD with stirring } \\
\cline { 3 - 4 } & $\begin{array}{c}\text { Only stirring } \\
\text { Electrode }\end{array}$ & Anode & Cathode \\
\hline Deposit weight $^{\mathrm{a}}$ on electrode $(\mathrm{mg})$ & 0.1 & 1.8 & 0.3
\end{tabular}

${ }^{a}$ Calculated from the average of three data. Area of the electrode plate immersed in DMF is $1.5 \mathrm{~cm} \times 0.75 \mathrm{~cm}$

${ }^{b}$ Averaged value of the two electrodes (cathode and anode).

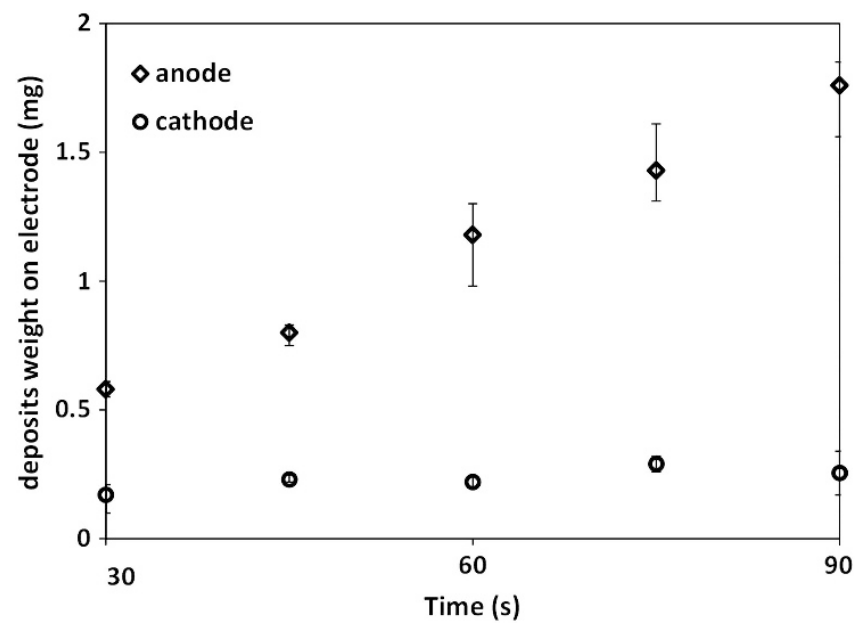

Figure 7 The change in the deposit weights on the cathode and anode (per $15 \mathrm{~mm} \times 7.5 \mathrm{~mm}$ ) as a function of EPD time (30V).

Oxone oxidation of the poly(ester-sulfide) gel

Oxone oxidation of the poly(ester-sulfide) (run 2, Table 1) to produce the corresponding poly(ester-sulfone) gel was also investigated by immersing the dried and fractured gel (powder size $<1 \mathrm{~mm}$ ) in a DMF solution containing two equivalents of Oxone per sulfide monomer feed at $40^{\circ} \mathrm{C}$ for $12 \mathrm{~h}$. The white, stiff gel could be obtained after extraction with distilled water in a Soxhlet apparatus. The presence of sulfonyl groups was confirmed by their IR and ATR absorbances at 1290 and $1126 \mathrm{~cm}^{-1}$ (Figure 5), and the degree of conversion of sulfide to sulfone was estimated by the ratio of the absorbance peaks at $1126 \mathrm{~cm}^{-1}$ and 1731 (ester) $\mathrm{cm}^{-1}\left(\mathrm{~A}_{1126} / \mathrm{A}_{1731}\right)$. In the ATR spectrum, peaks attributed to the sulfone were observed, and the absorbance ratio of $\mathrm{A}_{1126} / \mathrm{A}_{1731}$ (1.3) was comparable to that from the normal (transmittance) FT-IR spectrum $\mathrm{A}_{1126} / \mathrm{A}_{1731}$ (1.2). The results indicated that the Oxone oxidation occurred not only on the surface of the gel but also inside the gel to afford the corresponding poly(ester-sulfone) gel.

The thermal properties of the gels were observed by DSC measurements (Supplementary Figure S1). None of the gels exhibited the existence of a melting temperature. However, a significant increase in the glass-transition temperature $\left(T_{\mathrm{g}}\right)$ was observed after the oxidation of the poly(ester-sulfide) gel to the corresponding poly(ester-sulfone) gel, increasing from $-35^{\circ} \mathrm{C}$ to $13^{\circ} \mathrm{C}$. The high polarity of the sulfone functional groups causes electrostatic interactions, ${ }^{25}$ lowering the flexibility of the main chain and thus resulting in an increased $T_{\mathrm{g}}$. However, an improvement in the thermal stability of the gel after sulfonation was not observed (Supplementary Figure S2). The TGA curve indicated that the degradation temperatures of poly(ester-sulfide) and poly(ester-sulfone) gels, defined by the $5 \%$ weight loss, are 288 and $281^{\circ} \mathrm{C}$, respectively. 


\section{EPD of poly(ester-sulfone) gel in DMF}

To directly deposit the poly(ester-sulfone) gel onto stainless-steel substrates, we investigated the potential of using an EPD procedure, as shown in Figure 6. The results are summarized in Table 2. We observed that a trace amount of the poly(ester-sulfone) gel was deposited onto the stainless-steel substrate by simply stirring in DMF. However, the ability of the poly(ester-sulfone) gel to adhere to the stainless-steel anode was considerably improved under an electric field, and it appears that anode-selective deposition was achieved via the electrophoretic motion of polar sulfone in the heterogeneous state. It is suggested that the polarized sulfones dominate the surface of the gel. On the other hand, when using poly(ester-sulfide) gel before sulfonation, we did not observe any deposition on the substrates. We therefore concluded that the deposition of the gel on the anode was attributed to sulfonyl groups $\left(-\mathrm{SO}_{2}^{-}\right)$in the poly(estersulfone) segments.

To confirm the anode-selective deposition in the EPD procedure, the actual weights deposited on the cathode and anode (per $15 \mathrm{~mm} \times 7.5 \mathrm{~mm}$ ) were plotted as a function of the EPD time (Figure 7), in which at least three independent experiments were carried out to determine the reproducibility, and the average weights are plotted. During the EPD at $30 \mathrm{~V}$, the weight on the anode increased proportionally during $90 \mathrm{~s}$, although a remarkable increase in weight on the cathode was not observed, indicating that the anodeselective deposition of the poly(ester-sulfone) gels was predominant.

\section{CONCLUSION}

Although the thiol-ene 'click' reaction is well known as an efficient method for synthesizing certain functional polymers, in this study we utilized the thiol-yne/ene click copolymerization of BEM, BYM and TEGDT to synthesize a poly(ester-sulfide) gel, in which bis(butynyl) methyl succinate acted as the cross-linker, which was subsequently oxidized using Oxone to afford a poly(ester-sulfone) gel. The synthesized poly(ester-sulfone) gel was deposited onto a stainlesssteel electrode by EPD; however, the parent poly(ester-sulfide) gel was not deposited. These fundamental results should provide new guidance for fabricating novel materials for use as solid electrolytes.

\section{ACKNOWLEDGEMENTS}

This work was funded by the Ministry of Education, Science, and Culture of Japan (Grant-in-Aid for Development Scientific Research, no. 24550132).

1 Yoshino, N. Lithium ion secondary batteries; past 10 years and the future. J. Power Sources 100, 101-106 (2001).

2 Liu, S., Dougal, R. A., Weidner, J. W. \& Gao, L. A simplified physics-based model for nickel hydrogen battery. J. Power Sources 141, 326-339 (2005).

3 Winter, M., Besenhard, J. O., Spahr, M. E. \& Novak, P. Insertion electrode materials for rechargeable lithium batteries. Adv. Mater. 10, 725-763 (1998).
4 Ue, M., Ida, K. \& Mori, S. Electrochemical properties of organic liquid electrolytes based on quaternary onium salts for electrical double-layer capacitors. J. Electrochem. Soc. 141, 2989-2996 (1994).

5 O'Regan, B. O. \& Grätzel, M. A low-cost, high-efficiency solar cell based on dyesensitized colloidal $\mathrm{TiO}_{2}$ films. Nature 353, 737-740 (1991).

6 Kay, A. \& Grätzel, M. Low cost photovoltaic modules based on dye sensitized nanocrystalline titanium dioxide and carbon powder. Sol. Energy Mater. Sol. Cells 44, 99-117 (1996).

7 Allcock, H. R. \& Olmeijer, D. L. Polyphosphazenes functionalized with sulfone or sulfoxide groups: synthesis, characterization, and possible polymer electrolyte applications. Macromolecules 31, 8036-8046 (1998).

8 Sun, X. \& Angell, C. A. New sulfone electrolytes Part II. Cyclo alkyl group containing sulfones. Solid State Ionics 175, 257-260 (2004).

9 Xing, L., Vatamanu, J., Borodin, O., Smith, G. D. \& Bedrov, D. Electrode/electrolyte interface in sulfolane-based electrolytes for $\mathrm{Li}$ ion batteries: a molecular dynamics simulation study. J. Phys. Chem. C 116, 23871-23881 (2012).

10 Schuster, M., Araujo, C. C., Atanasov, V., Andersen, H. T., Kreuer, K. \& Maier, J. Highly sulfonated poly(phenylene sulfone): preparation and stability issues. Macromolecules 42, 3129-3137 (2009).

11 Shao, N., Sun, X., Dai, S. \& Jiang, D. Oxidation potentials of functionalized sulfone solvents for high-voltage Li-ion batteries: a computational study. J. Phys. Chem. B 116, 3235-3238 (2012).

12 Sun, X. \& Angell, C. A. New sulfone electrolytes for rechargeable lithium batteries.: Part I. Oligoether-containing sulfones. Electrochem. Commun. 7, 261-266 (2005).

13 Takasu, A., Oishi, Y., lio, Y., Inai, Y. \& Hirabayashi, T. Synthesis of aliphatic polyesters by direct polyesterification of dicarboxylic acids with diols under mild conditions catalyzed by reusable rare-earth triflate. Macromolecules 36, 1772-1774 (2003).

14 Takasu, A., lio, Y., Oishi, Y., Narukawa, Y. \& Hirabayashi, T. Environmentally benign polyester synthesis by room temperature direct polycondensation of dicarboxylic acid and diol. Macromolecules 38, 1048-1050 (2005).

15 Takasu, A., Takemoto, A. \& Hirabayashi, T. Polycondensation of dicarboxylic acids and diols in water catalyzed by surfactant-combined catalysts and successive chain extension. Biomacromolecules 7, 6-9 (2006)

16 Takasu, A., Narukawa, Y. \& Hirabayashi, T. Direct dehydration polycondensation of lactic acid catalyzed by water-stable Lewis acids. J. Polym. Sci. Part A: Polym. Chem 44, 5247-5253 (2006).

17 Takasu, A., Shibata, Y., Narukawa, Y. \& Hirabayashi, T. Chemoselective dehydration polycondensations of dicarboxylic acids and diols having pendant hydroxyl groups using the room temperature polycondensation technique. Macromolecules 40, 151-153 (2007).

18 Takasu, A., Makino, T. \& Yamada, S. Polyester synthesis at moderate temperatures via the direct polycondensation of dicarboxylic acids and diols catalyzed by rare-earth perfluoroalkanesulfonates and bis(perfluoroalkanesulfonyl)imides. Macromolecules 43, 144-149 (2010).

19 Takasu, A., lio, Y., Mimura, T. \& Hirabayashi, T. Room-temperature polycondensation of dicarboxylic acids and diols catalyzed by water-stable lewis acids. Polym. J. 37, 946-953 (2005).

20 Takasu, A., Shibata, Y., Narukawa, Y. \& Hirabayashi, T. Chemoselective dehydration polycondensations of dicarboxylic acids and diols having pendant hydroxyl groups using the room temperature polycondensation technique. Macromolecules 40, 151-153 (2007).

21 Shibata, Y. \& Takasu, A. Synthesis of polyester having pendent hydroxyl groups via regioselective dehydration polycondensations of dicarboxylic acids and diols by low temperature polycondensation. J. Polym. Sci. Part A: Polym. Chem. 47, 5747-5757, 59 (2009).

22 Takasu, A. \& Yamamoto, K. Preparation of gelatinous reversible addition-fragmentation chain transfer agents 'RAFT Gel' via chemoselective polycondensations of a dicarboxylic acid containing a mercapto group and diols. Macromolecules 43, 8519-8523 (2010).

23 Nagao, Y., Takasu, A. \& Boccaccini, A. R. Anode-selective electrophoretic deposition of a bioactive glass/sulfone-containing click polyester composite. Macromolecules 45, 3326-3334 (2012).

24 Fairbanks, B. D., Scott, T. F., Kloxin, C. J., Anseth, K. S. \& Bowman, C. N. Thiol-yne photopolymerizations: novel mechanism, kinetics, and step-growth formation of highly cross-linked networks. Macromolecules 42, 211-217 (2009).

25 Handbook of Chemistry and Physics. 66th edn (ed. Weast, R. C.) (CRC Press, Boca Raton, FL, USA, 1985).

Supplementary Information accompanies the paper on Polymer Journal website (http://www.nature.com/pj) 